\title{
Pumping Up the Citizen Muscle Bootcamp: Improving User Experience in Online Learning
}

\author{
Beth Karlin ${ }^{1}$, Birgit Penzenstadler ${ }^{2}$, and Allison Cook $^{3}$ \\ ${ }^{1}$ School of Social Ecology, University of California, \\ Irvine, 300 Social Ecology I, Irvine, California, 92697-7075 \\ bkarlin@uci.edu \\ ${ }^{2}$ School of Information and Computer Sciences, \\ University of California, Irvine, 314 Donald Bren Hall, Irvine, California, 92697-7075 \\ bpenzens@uci .edu \\ ${ }^{3}$ Story of Stuff Project, 1442 A Walnut Street \#272, Berkeley, CA, 94709 \\ allisonestoryofstuff.org
}

\begin{abstract}
This paper introduces and presents preliminary findings from the Citizen Muscle Bootcamp (CMB), an online learning program designed by The Story of Stuff Project for environmental activism. We first introduce the program and its potential to leverage online learning for citizenship training. Next, we report findings from two pilot studies in which we identify strengths and weaknesses of the current user experience. Finally, we present a revised course design that integrates insights from the fields of HCI, psychology, and requirements engineering to improve participant engagement and retention. Suggestions focus on variables related to recruitment, topic, process, and completion to identify key leverage points for improving user experience. It is our hope that this partnership represents the potential of research to inform practice to support best practices in HCI for sustainability.
\end{abstract}

Keywords: sustainability, citizenship, online learning, user experience.

\section{Introduction}

"I know of no safe depository of the ultimate powers of the society but the people themselves; and if we think them not enlightened enough to exercise their control with a wholesome discretion, the remedy is not to take it from them, but inform their discretion." Thomas Jefferson (1820)

Our democracy relies just as much upon the participation of its citizens today as it did when it was founded. We are facing tough issues as a nation and a planet that require the active participation of its citizens. Our democracy is based on an educated and empowered citizenry holding elected officials accountable for their actions and decisions. When the citizens do not take up this critical check in our system of checks and balances, we leave all of our decisions to the politicians and the lobbyists who inform and persuade them. As voter turnout continues to decline, many public and private institutions are looking for ways to increase civic knowledge, interest, and participation among the public. 
With the rise of time spent online across demographic groups, web content has become an increasingly common way of disseminating important information to people and engaging them in social causes. However, the sheer quantity of content online makes it vital that any program attempting to engage and retain an audience for longer than a few minutes focus on user experience. Human computer interaction (HCI) as a field addresses how to best approach the questions of how people interact with online content and how to maximize it for the best possible user experience and response.

This paper introduces and presents preliminary data on the Citizen Muscle Bootcamp (CMB), an online learning program designed by The Story of Stuff Project for environmental activism. The goal of the bootcamp is to train some of the 500,000 members of the Story of Stuff community into citizen activists to work toward social change on sustainability issues. After introducing the project, we analyze data from the first two pilot studies to identify key areas within the Citizen Muscle Bootcamp in which principles from HCI can be integrated to improve user experience. We then present a re-designed user experience of the course to leverage our insights from the fields of psychology and software engineering. These include variables related to recruitment, topic, process, and completion. As a result of this new design, we hope to improve the user experience so that interested participants in the Citizen Muscle Bootcamp will be better targeted to the right courses for them and provided with reinforcement and accountability throughout the course, leading to increased engagement, retention and subsequent civic engagement with the organization and its campaigns.

\section{Theoretical Foundations}

In this section, we will briefly point out the foundations for this work in the areas of sustainability and technology, online learning, user experience, and requirements engineering.

\subsection{Sustainability and Technology}

The term sustainability refers to the ability "to last or continue for a long time" [1] and the United Nations [2] has defined sustainable development as that which "meets the needs of the present without compromising the ability of future generations to meet their own needs". Scientists have shown that the behavior of humans has caused unprecedented changes to the earth's atmosphere; achieving a sustainable planet must involve changes in the habits and behaviors of individuals and communities, especially in the developed world.

While technological innovation (e.g., extraction and use of fossil fuels) has certainly enabled this growth, technology also has the potential to support solutions to key sustainability issues [3]. Technologies such as virtual reality, social media, and mobile technology enable humans to interact, not only with computers, but through computers with other people and with their natural and built environments. Thus, the 
potential of Human Computer Interaction (HCI) research is vital and important to the study of sustainability.

\subsection{Online Learning}

One way of leveraging technology to connect people and ideas is through online learning. The philosophy of freely sharing information and the pervasiveness of the Internet have created many new opportunities for teaching and learning [4]. People have to be confident and competent in using the different tools provided, and it takes time for people to feel comfortable to learn in an autonomous fashion. Collaboration, creativity, and a flexible mindset are vital for active learning in a changing and complex learning environment [5]. In a study on students' perceptions of characteristics of online courses [6], most agreed that course design, learner motivation, time management, and comfortableness with online technologies impact success. Elaborating on the advantages and drawbacks of online courses, Daphne Koller summarizes the success of Coursera: "Online course content has been available for a while. What made it different was that it was a real course experience, it started on a given day, and then the students would watch videos on a weekly basis and do homework assignments" [7].

\subsection{Design and User Experience}

A key function of HCI research is to assess the subjective user experience of computer systems, programs, and interfaces [8]. As such, HCI research has identified several key characteristics related to user experience. While a simple definition of usability refers to "ease of use", more comprehensive definitions take into account several characteristics [9].

One common definition of usability includes the following five key characteristics: effectiveness, efficiency, error tolerance, ease of use, and engagement [9]. The first three refer to the users' ability to complete program tasks. A program is effective if the user is able to complete the task, efficient if it can be done fairly quickly, and error tolerant if it can be completed with few to no errors. Ease of use and engagement refer to the users' experience within the program. A program is easy to use when the user feels relatively confident navigating it and engaging when the system or interface is pleasing and satisfying to use. These last two variables are particularly important in predicting the degree to which people accept, use, and are loyal to particular information technologies [10].

\subsection{Requirements Engineering}

Requirements engineering (RE) is the branch of software engineering concerned with the real-world goals for, functions of, and constraints on software systems [11]. Requirements engineering is concerned with interpreting and understanding stakeholder terminology, concepts, viewpoints and goals. Hence, RE must concern itself with an understanding of beliefs of stakeholders (epistemology), the question of 
what is observable in the world (phenomenology), and the question of what can be agreed on as objectively true (ontology). Such issues become important whenever one wishes to talk about validating requirements, especially where stakeholders may have divergent goals and incompatible belief systems [12]. RE facilitates the process of consolidating different stakeholders' concerns and agreeing on a system vision [13]. One method to transform the use cases of a system vision into more detailed descriptions of the interaction between user and system is to write user stories [14].

\section{Project Background: Introducing the Bootcamp}

One way of overcoming the cognitive complexity of climate science is through media and storytelling approaches. Dozens of films related to sustainability issues such as water, climate, food, and transportation have been released over the past decade. Research has shown that films such as An Inconvenient Truth and Food Inc. have the ability to impact viewers' knowledge and attitudes around sustainability issues $[15,16]$. Many issue-based films are working to extend their influence through transmedia social action campaigns. Such campaigns combine the film with new technologies such as streaming video, social media and network applications, allowing viewers to engage in the issues presented to learn more, connect with others, and get engaged to take action.

\subsection{The Story of Stuff Project}

One example of such a campaign is The Story of Stuff Project. Story of Stuff started as a film project in 2007 designed to tell the story of "stuff (i.e. consumer goods) from its creation, through its sale and use, and eventually to its disposal" in a catchy and engaging manner. The single film, with an initial viewership goal of 50,000 views, quickly exceeded this goal and sparked the launch of The Story of Stuff Project as a 501(c)3 nonprofit organization.

The Story of Stuff Project has since created 8 additional films and has also translated into other mediums, including television (interstitials for PBS), print (Story of Stuff book), online (website, social media), curricula (K-12 and religious groups), and a podcast. Their combined films have been translated into 39 languages and seen by over 40 million people and counting. This viewership has also translated into an active online community of nearly a half million people.

The initial goal of the project was to create and provide media resources to environmental activists and educators as well as to the general public. All Story of Stuff media have a Creative Commons license and are free to distribute for any noncommercial use. However, a community of potential activists formed around the organization, who started to want to become more actively engaged in the issues discussed in the films. They began communicating with staff via social channels and email that they were excited about the issues discussed in the film and wanted to do more. It became clear that educating people on the "story of stuff" was important but equally important was equipping and engaging them to act upon the knowledge they had gained through the films. 


\subsection{Citizen Muscle Bootcamp}

To address this need, The Story of Stuff Project created a new program in 2013 called the Citizen Muscle Bootcamp. The Citizen Muscle Bootcamp is a six-week, online program designed to provide Story of Stuff Project community members with the skills, motivation and peer support they need to act on issues related to environmental sustainability. It was designed in response to inquiries and requests from the Story of Stuff community to help members learn, engage, connect, and act on the issues raised in their films.

Modeled on other successful multi-week online engagement programs-for weight loss [17] or financial literacy [18,19], for example-the Citizen Muscle Bootcamp guides participants through a series of weekly trainings aimed at strengthening their civic activism skills, or "citizen muscle". Each week of the program focuses on a unique skill:

1. Purpose: discovering your change making style and goal

2. Talk: learning how to communicate effectively about your issue

3. Grow: finding and developing a community of allies

4. Focus: getting strategic about how to accomplish your goals

5. Push: figuring out which tactics you'll need to employ to effect change

6. Practice: putting your learning into action.

Members of the Story of Stuff community were contacted via email and invited to register for the course free of charge. Those who registered were enrolled in the course as participants. Each week, participants received an email with a link to a 2-3 minute video lesson, accompanied by additional resources (e.g., framing, tips, readings) to get them practicing their change-making skills and a homework activity to put their new skills into practice. The program was designed so that each weekly module could be completed in 1-2 hours per week.

Even though the Story of Stuff Project was able to recruit participants to register, retention has been low and reported outcomes mixed. In the following sections, we will discuss the first two pilots of the Citizen Muscle Bootcamp and propose a revised design to improve user experience.

\section{$4 \quad$ Learning from Pilot Studies: Testing the Bootcamp}

Two rounds of pilot testing of the bootcamp were conducted in 2013. All participants were asked for feedback both before and after the bootcamp to assess strengths, weaknesses, and opportunities for improvement.

\subsection{Measures}

For the first pilot, participants received an initial intake survey at the beginning of the course and an exit survey at the end. The second pilot also had an intake survey; instead of an exit survey, they received a follow-up survey six months after the program. 
The intake survey included questions about demographics (gender, age) as well as past experience (civic engagement, training, involvement with other organizations), current skills and abilities, community involvement, perspectives on the best way to make change, barriers to change, and motivation to take part in the bootcamp.

The exit survey for the first pilot asked about units they completed and which were most helpful as well as feedback on program length, level of interaction, interface, organizational support, and adaptations that would increase participation. They also repeated questions from the intake survey regarding current skills and abilities, perspectives on the best way to make change and barriers to change, community involvement, and motivation to participate.

The follow-up survey for the second pilot asked participants what they learned from the program, what specific actions they had taken as a result of their participation, their self-reported outcomes related to knowledge, skills, and leadership, and their most rewarding and challenges parts of the experience.

\subsection{Participants}

51 people participated in the first and 342 in the second pilot. The intake surveys revealed a diverse group of participants with a wide range of experiences and perspectives. Ages ranged from 18 to 74 with approximately $2 / 3$ women and 1/3 men. About a quarter came with over a decade of "changemaker" experience and another quarter had less than a year of experience. Table 1 presents summary data on demographic variables for the two pilot samples compared to U.S. Census data (2010) as well as and average number of years as a changemaker.

Table 1. Characteristics of the pilot samples compared to US Census data

\begin{tabular}{lcccc}
\hline Variable & Pilot 1 & $\begin{array}{c}\text { Pilot 2- } \\
\text { General }\end{array}$ & $\begin{array}{c}\text { Pilot 2 } \\
\text { Plastics }\end{array}$ & Census \\
\hline Gender & 32\% Male & $33 \%$ Male & $32 \%$ Male & $49 \%$ Male \\
Average age & 41.3 Years & 46.9 Years & 44.8 & 36.8 Years \\
\# of years as a changemaker & 4.8 & 4.9 & 5.0 & --
\end{tabular}

\subsection{Importance of Citizen Muscle Bootcamp}

The intake surveys provided insights that supported the need for citizenship training such as the Citizen Muscle Bootcamp. For example, $61 \%$ of participants reported that their skills and abilities as a changemaker were either "underdeveloped" or "very underdeveloped" and the most frequently reported motivation for participating in the course was to develop and/or refine existing "changemaker" skills (see Table 2). Over half $(53 \%)$ said they had never received any formal or informal training on the being a changemaker. 
Table 2. Motivation for participating in Citizen Muscle Bootcamp

\begin{tabular}{lc}
\hline Reason & Percentage \\
\hline Develop changemaker skills & $33 \%$ \\
Refine existing skills & $30 \%$ \\
Learn to plug into action on issues & $27 \%$ \\
Connect with other changemakers & $11 \%$
\end{tabular}

In addition, $50 \%$ felt that the best way they could make change was "through conscious lifestyle and shopping choices" as opposed to "voting" or "organizing in their community." This reaffirmed the significant opportunity (and need) to help people shift their primary change-making identity from consumer to citizen.

\subsection{Outcomes of Citizen Muscle Bootcamp}

Overall, the participants who completed the bootcamp reported positive outcomes. They reported increases in knowledge, skills, and likelihood to engage in work for a sustainable planet (see Table 3).

Table 3. Outcomes of Bootcamp on a scale of 1 (strongly disagree) to 5 (strongly agree)

\begin{tabular}{lc}
\hline Statement & Average \\
\hline My knowledge about the skills needed to flex my Citizen Muscle have & 3.80 \\
increased. & \\
The information provided was useful & 4.25 \\
I developed leadership skills that I can use in my life. & 3.65 \\
I am more likely to engage in work for a healthy, sustainable, and just planet. & 4.00
\end{tabular}

Participants reported learning about "how to try and influence people without just rattling off boring facts" and "what it takes to lead and to create change that is grounded, focused, and effective". Some reported that they already knew most of the material but that it was a nice refresher for them.

Most rewarding aspects reported by participants included "getting to do something new", "resources and learning new ideas on advocacy and activism", and "knowing that other people around the world were participating".

\subsection{Challenges of Citizen Muscle Bootcamp}

We identified three key challenges for participants based on survey results: project focus, interaction, and program length.

Focus. The first pilot featured a general curriculum for anybody interested in citizenship and activism training. While there are benefits to such an open approach, the lack of a clear issue focus created challenges for quite a few participants. For example, the first week of the Bootcamp focused on identifying the participant's core 
purpose as a changemaker. While participants clearly enjoyed the Purpose unit (it was one of the top rated weeks), a number of participants voiced concerns that either their purpose was too vague or that it was too difficult to select one or that they wanted to feel more connected to the work of the Story of Stuff Project. Ultimately, they wanted more direction as to what to work on.

In the second round of pilot testing, project organizers ran two bootcamps simultaneously. The first maintained the broader approach from the first round and the second focused specifically on one of the project's core campaign areas-plastic pollution-with a central goal of preparing participants to work on plastic bag bans in their communities.

Interaction. The bootcamps took place exclusively online with opportunities for interaction limited to the blog and Google Hangout. Several participants requested more interaction with the other people going through the bootcamp. They wanted to be part of a peer group going through the program and feel that sense of connection.

Program organizers attempted to increase the interaction of the bootcamp in the second pilot, with preliminary but limited success. Program organizers reached out via personal email to try and get people to organize in-person groups; two individuals responded positively but no groups were made. They also hosted a webinar in the middle of the seminar for participants to interact with Annie Leonard, the project director, and each other. They experienced technical difficulties and Annie was not able to join, but dozens of participants stayed online and chatted for a half hour with one another.

Time. The most commonly reported challenge by participants was that of limited time: Several reported that they "didn't always manage to complete the task on time" and that "keeping $100 \%$ on top of the activities week to week" was very difficult. The six-week length of the program also posed some participation challenges, given the hectic nature of most people's daily lives. The first pilot had 56 shared comments in Week 1; by Week 3 that number had dropped to 12. The significant drop-off in engagement was also reflected in participants' email click through rates. Although some attrition is normal and expected, it is hoped that an improved user experience will combat some of this.

\section{$5 \quad$ Redesign: Pumping Up the Bootcamp}

We identified the following key variables for re-design: recruitment, topic, process, and completion. Re-designing the user experience of the course leverages insights from the fields of psychology and software engineering to improve recruitment, retention, and outcomes.

\subsection{Recruitment}

The way in which participants are recruited and/or invited to participate has impacts on how they view and experience the subsequent course. Robert Cialdini [20] 
identified six key principles of influence that can be used to maximize compliance: scarcity, commitment, social proof, liking, authority, and reciprocity. Deploying these principles via message framing in the recruitment process can enhance participants' commitment to complete the course. A scarcity appeal, for example, emphasizes limited availability or the potential to lose an opportunity if not acted upon. We predict that recruitment messaging reminding participants that they are taking a limited spot in the bootcamp will enhance their desire to participate and subsequent commitment to complete the course (since they took what is seen as a limited spot). Following such an appeal with a commitment message, by formally asking participants to commit to complete the course before they agree to sign up, can further increase retention.

Additionally, engaging the principle of social proof by encouraging participants to share on their social media sites when they sign up, liking by creating personalized messages from Annie Leonard (founder and spokesperson for The Story of Stuff Project), authority by bringing on key figures in the environmental movement to promote the course, and reciprocity by emphasizing how the organization is providing this course and their other media resources free of charge will be tested for their ability to increase response in the form of email click through numbers, registrations, and subsequent course retention.

\section{$5.2 \quad$ Topic}

As mentioned above, several participants in the general bootcamp mentioned being unclear on how or where to utilize their newly acquired skills in their communities. Creating issue-specific bootcamps can provide such specific targets for action that participants can take individually and together as a community.

This variable was already tested in the second bootcamp pilot. The plastics-focused bootcamp had both higher participation numbers and improved outcomes over the general bootcamp. Since it had a goal of engaging participants to work on plastic bag ban initiatives, they had a clear direction to guide their engagement in the course. We plan to test this variable again in the next iteration of the program.

\subsection{Process}

The user experience in the initial pilot studies was a largely individual one. Participants engaged with the course material but had very little interaction with one another. Since many participants expressed an interest in meeting other changemakers, including an interactive element is hypothesized to increase engagement and subsequent retention.

To test this idea, we plan to test three different levels of "social experience" in the bootcamp: individual experience, online cohorts, and local cohorts. The three differ in the following ways:

1. Individual experience: Similar to pilots described above; anonymous; engage with content; doing exercises 
2. Online cohort: Participants matched online by the program organizers; groups meet online and communicate throughout the course.

3. Local community: Participants asked to form place-based learning groups in their community; convening groups locally to participate together in person

\subsection{Completion}

Providing rewards for completion of a task can be a compelling motivational factor [21]. Although rewards can be tangible in the form of a certificate, ribbon, or t-shirt, non-monetary rewards such as a virtual badge or title may also be effective. As such, the next pilot will provide a formal recognition of completion in the form of an online certificate, virtual badge to display on social media, and an invitation to join a special group of advisors to the Story of Stuff Project which is limited to those who have completed the bootcamp.

Additionally, some participants found the time commitment of the course difficult to complete, suggesting a shorter duration may enhance completion. The next bootcamp will be broken into two parts, with the initial "Citizen Muscle Bootcamp" being four weeks long, with a follow-up "advanced" course for those who complete the initial program.

\subsection{User Stories}

User stories enable program staff and web developers to community about the desired user experience, which influences many programming decisions. We developed a set of user stories to describe the interaction of the user with the system. An overview of these stories is provided in Figure 1. A sample user story for the login process of a user in the online cohort is:

1. John Smith logs into the system and creates a profile

2. After completing the profile, he is directed to the homescreen of the bootcamp

3. On his dashboard, he sees:

- His profile

- All course units

- A marker representing "Start Here" or "You are here"

- A list of Group Members and links their profiles

- The dates/times for group Google Hangouts

After clicking around the different user profiles, John begins the first unit. 


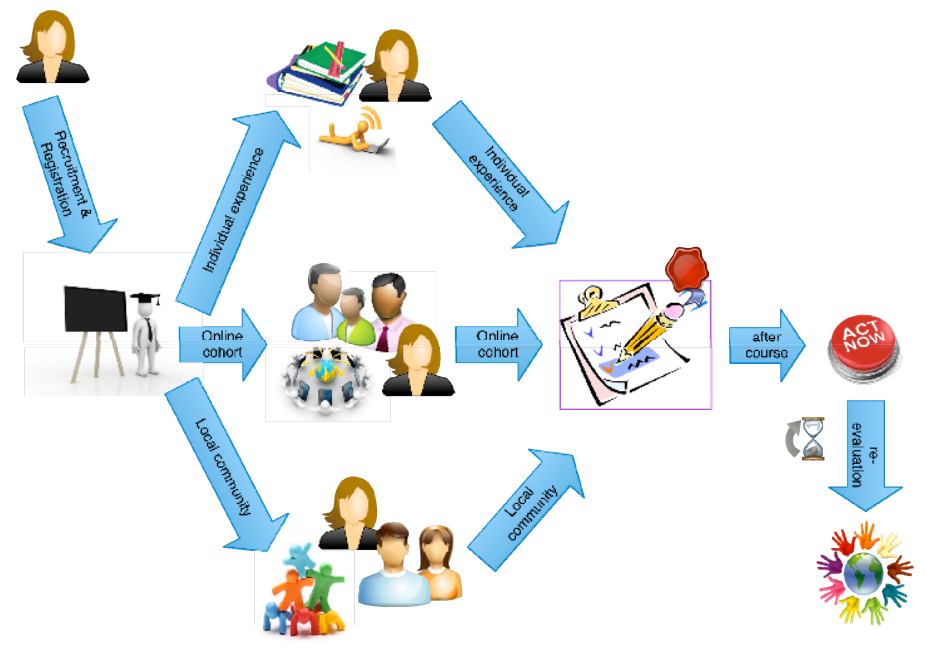

Fig. 1. Overview of the user stories and the redesign

\section{Conclusion}

The Citizen Muscle Bootcamp builds on insights from the fields of psychology and human computer interaction to create a online learning environment for citizenship. Through improved design, it is our hope that people will be better targeted to the right courses for them, complete the bootcamp program, and go on to use the knowledge gained to become active in their local and global communities.

This project was designed to have both practical and theoretical impacts. Practical impacts include a positive influence on civic engagement by teaching participants the skills that enable them to take action on important sustainability issues. Theoretical impacts include the testing of key usability variables related to influence, commitment, online social experience, and rewards that can be replicated in other programs in the future.

It is our hope that this project presents an example of the potential to be gained from action research partnerships between university researchers and non-profit organizations working together to promote individual and collective behavior for sustainability. In addition to improving the bootcamp for all subsequent participants, such analysis of user engagement with online learning systems for the purpose of sustainability education and pro-active engagement is a topic with much potential for other organizations as well. Future work will execute the study and report on results.

\section{References}

1. Merriam-Webster: Sustainable (2013), http: / / www.merriam-webster.com/dictionary/sustainable

2. United Nations, Our Common Future (1987), http: / / www . un-documents. net/ocf-02.htm\#I 
3. Karlin, B.: Technology and Psychology - Natural enemies or just plain natural? Ecopsychology 5(4), 217-218 (2013)

4. Martin, F.G.: Will massive open online courses change how we teach? Commun. ACM 56(8), 26-28 (2012)

5. Kop, R.: The challenges to connectivist learning on open online networks: Learning experiences during a massive open online course. The International Review of Research in Open and Distance Learning, Special Issue-Connectivism: Design and Delivery of Social Networked Learning 12(3) (2011)

6. Song, L., et al.: Improving online learning: Student perceptions of useful and challenging characteristics. The Internet and Higher Education 7(1), 59-70 (2004)

7. Kohler, D.: What we're learning from online education (2012), http://www.ted.com/talks/daphne_koller_what_we_re_learning_ from_online_education.html

8. Card, S.K., Moran, T.P., Newell, A.: The Psychology of Human-Computer Interaction. Lawrence Erlbaum Associates (1983)

9. Quesenbery, W.: What Does Usability Mean: Looking Beyond 'Ease of Use'. In: Proceedings of the 48th Annual Conference, Society for Technical Communication (2001)

10. Davis, F.D.: Perceived usefulness, perceived ease of use, and user acceptance of information technology. MIS Quarterly, 319-340 (1989)

11. Zave, P.: Classification of research efforts in requirements engineering. ACM Computing Surveys 29(4), 315-321 (1997)

12. Nuseibeh, B., Easterbrook, S.: Requirements Engineering: A Roadmap. In: Proceedings of the Conference on the Future of Software Engineering, pp. 35-46. ACM, New York (2000)

13. Monk, A., Howard, S.: The Rich Picture: A Tool for Reasoning about Work Context. Interactions 5(2), 21-30 (1998)

14. Cohn, M.: User stories applied: For agile software development. Addison-Wesley, Pearson Education, Boston (2004)

15. Nolan, J.: "An Inconvenient Truth" Increases Knowledge, Concern, and Willingness to Reduce Greenhouse Gases. Environment and Behavior 42, 643-658 (2010)

16. Blakley, J.: Movies for a Change (2012),

http: / / www . youtube.com/watch?v=Pb0FzPzzWuk

17. Glasgow, R., Nelson, C.C., Kearney, K.A., Reid, R., Ritzwoller, D.P., Strecher, V.J., Couper, M.P., Green, B., Wildenhaus, K.: Reach, Engagement, and Retention in an Internet-Based Weight Loss Program in a Multi-Site Randomized Controlled Trial. J. Med. Internet Res. 9(2), e11 (2007)

18. Siegel Bernard, T.: Finance Class on the Web, for Students of All Ages. New York Times (2013)

19. Federal Deposit Insurance Corporation: Money Smart: A Financial Education Program (2012), http: / /www. fdic.gov/consumers / consumer/moneysmart / $\mathrm{mscbi} / \mathrm{mscbi}$.html

20. Cialdini, R.: Influence: The Psychology of Persuasion. William Morrow and Company (1984)

21. Deci, E.L., Koestner, R., Ryan, R.: A Meta-Analytic Review of Experiments Examining the Effects of Extrinsic Rewards on Intrinsic Motivation. Psychological Bulletin 125(6), 627-668 (1999) 